\title{
An Investigation of Less Export of Readymade Garments to Non-Traditional Markets by Bangladesh and Justification of Increasing Export
}

\author{
Abir Khan, \\ Sayed Hasan Mahmud, \\ Lecturers, Textile Engineering, \\ National Institute of Textile Engineering and Research, Bangladesh
}

Doi:10.19044/esj.2020.v16n10p216 URL:http://dx.doi.org/10.19044/esj.2020.v16n10p216

\begin{abstract}
This paper focuses on the current condition of readymade garments export by Bangladesh to well-established export destinations and nontraditional destinations. The main objective of this study is to find out ways of increasing Bangladesh's export earnings. The RMG industry has set an export target of US $\$ 50$ billion by 2021 for which new export destinations must be explored. Bangladesh, however, is still far behind the target due to some constraints. Another objective of this study is to identify these constraints and justify the reasons to explore the non-traditional markets. This study was conducted using secondary data obtained from various trusted national sources. These data were analyzed and showcased using statistical tools to interpret the discussed topic.
\end{abstract}

Keywords: RMG Export, Market Exploration, Diversification

\section{Introduction}

Bangladesh's export largely depends on the apparel industry. This sector contributes $11.17 \%$ to its GDP in the Fiscal Year 2017-2018 according to BGMEA. However, this contribution to GDP has been declining (Dhaka Tribune, April 2019). So it can be said that the country's economy will grow further if this industry gets bigger. Since this is an export-oriented industry, the industry needs to explore different horizons for export in order to achieve a sustainable growth. Depending on the traditional markets only will not give security to its continuous growth. If Bangladesh have to achieve its target of apparel export worth $\$ 50$ billion by 2021, then export to non-traditional markets must increase. Although Bangladesh has already been exporting apparel to non-traditional markets like Australia, Brazil, Chile, China, India, Japan, Korea, Mexico, Russia, South Africa, Turkey, UAE, Hong Kong, etc., 
the volume is not growing expectedly. This paper highlights the underlying facts of low export to these non-traditional market and how to overcome the situtation. Traditional markets have been defined as the countries where majority of readymade garments are exported to. From this context, countries such as United Kingdom, USA, Germany, Spain, France, and Canada are considered traditional markets for Bangladesh. Non-traditional markets are considered to have lower export of readymade garments from Bangladesh. Therefore, countries such as Turkey, Hong Kong, Saudi Arabia, Japan, China, Brazil, and Australia falls into the non-traditional market category.

\section{Methodology}

This study is entirely based on secondary data collected from different trusted sources. The researchers did not have to visit factories for primary data collection. Data were collected through different Research Journals, Thesis papers, newspapers and survey reports, BGMEA Yearly report, Export Promotion Bureau Yearly reports. The data was scanned from the secondary sources. After the data has been collected, descriptive analysis was used to illustrate the data. For the first phase, the study shows the underlying reasons for lower export to non-traditional market, while the later phase discusses the steps that can be taken to improve the export figures to non-traditional markets.

\section{Result}

With data collected for Export Promotion Bureau, the bar charts below can be constructed:

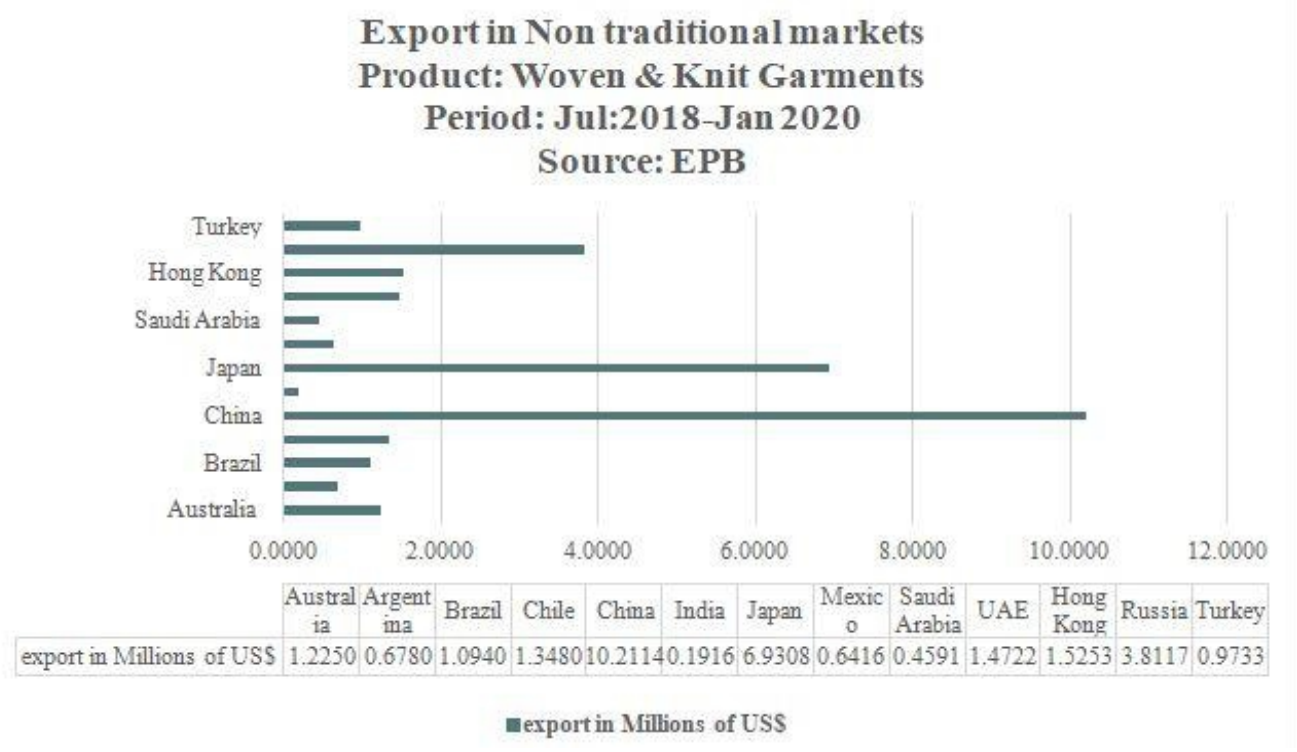

Figure 1. RMG export to non-traditional market by Bangladesh 


\section{Export to traditional market USA \& European countries \\ Product: Woven \& Knitwear \\ Period: July:2018-Jan:2020 \\ Source: EPB}

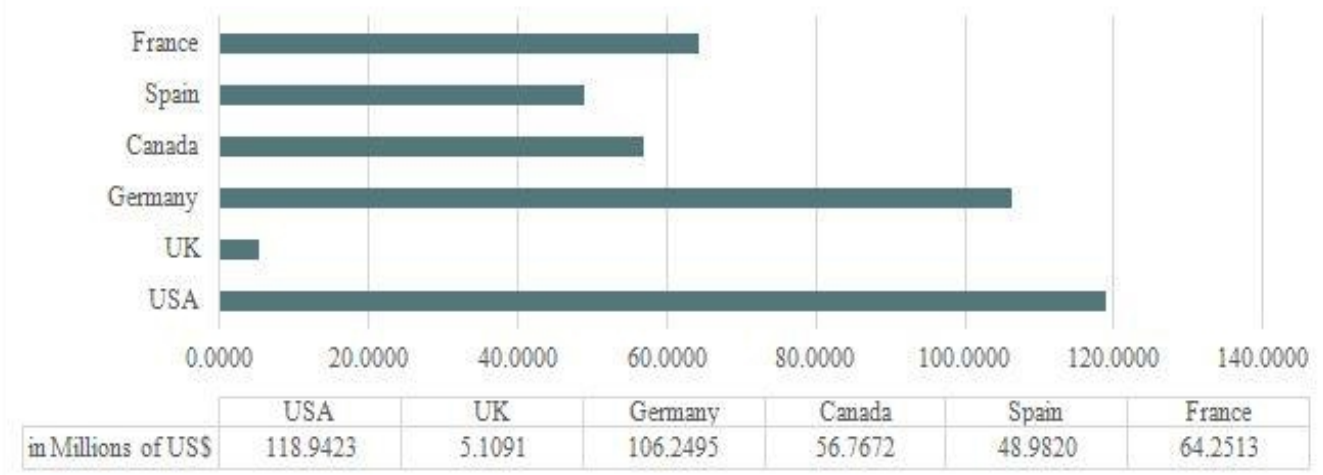

min Millions of USS

Figure 2. RMG export to traditional market by Bangladesh (Source: Export Promotion Bureau)

Combining these two charts, we may get the total export in traditional and non-traditional market:

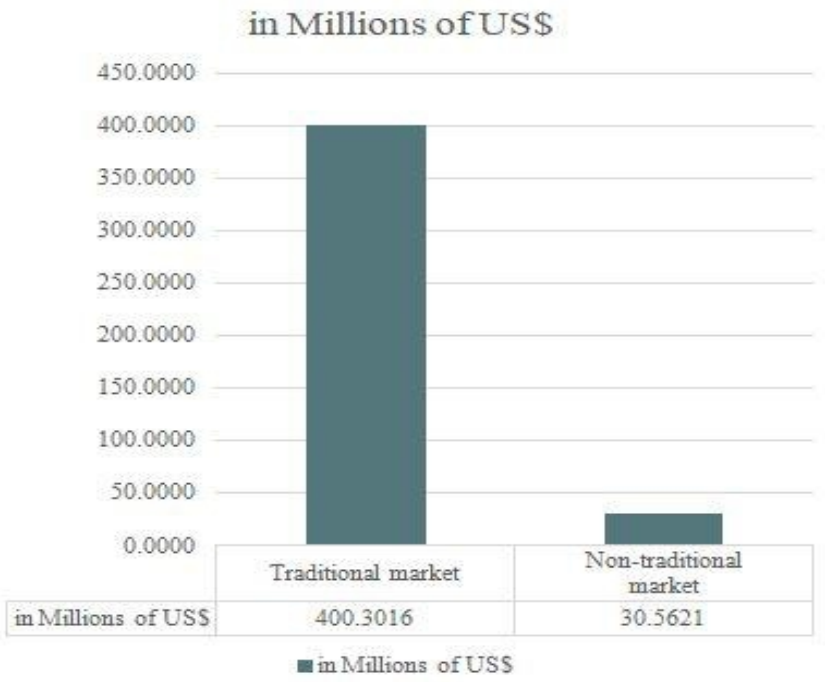

Figure 3. RMG export to traditional \& non-traditional market by Bangladesh (Source: Export Promotion Bureau) 


\section{Analysis}

\section{Underlying Reasons for Lower Export to Remote Markets}

\section{Export-duty}

When a country exports its manufactured goods to another country, export duty plays a major role in terms of prices, business expansion, stability, etc. The non-traditional markets for Bangladesh are charging a stiff number for export into their countries. These are numbers higher than traditional markets. So both parties, the exporter and the importer, involved in the business are not willing to expand their business. Thus, the bar chart below shows some of the non-traditional market's export duty that Bangladesh needs to pay for export:

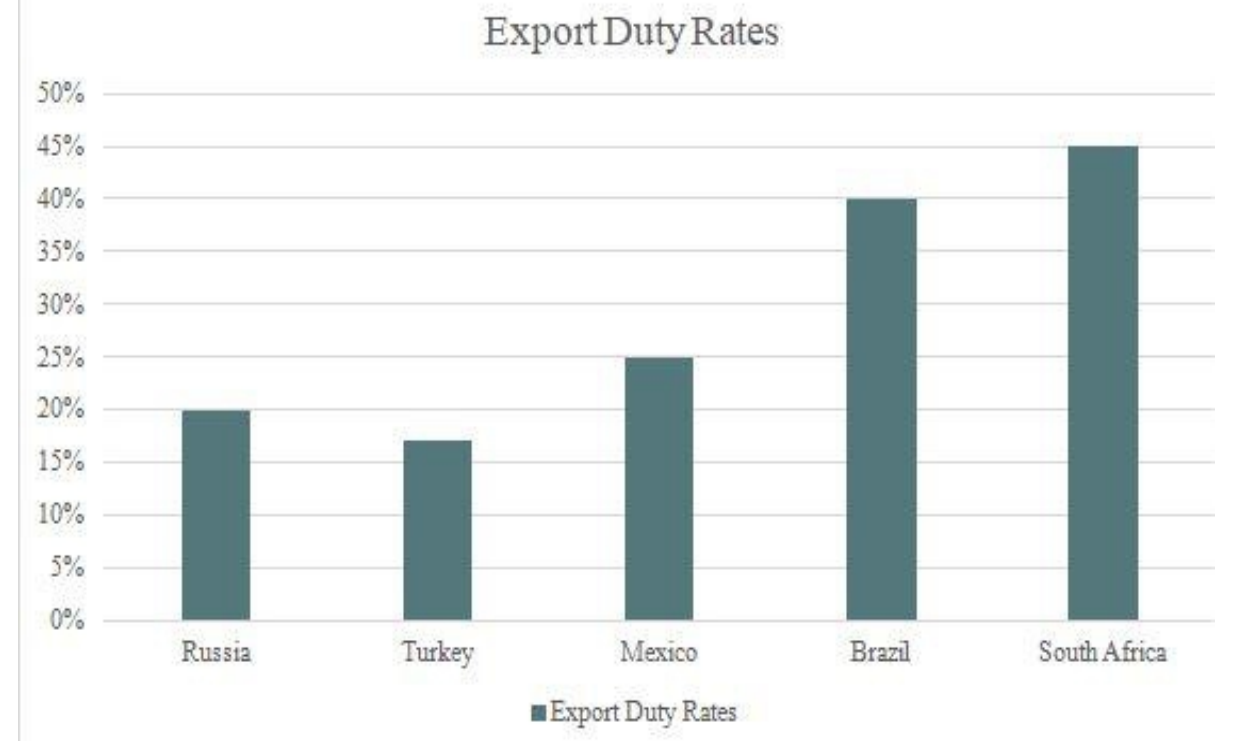

Figure 4. Export duty to non-traditional market for Bangladesh

\section{Lack of Marketing Effort}

Bangladesh's RMG industry does not focus much on promotional activities such as Fashion Show, Trade Show, Design Studio, and factory outlet. Thus, a promotion related marketing barrier has been created. Also, the marketers employed in this sector have poor marketing skills and competency. Hence, the lack of marketing effort is restricting Bangladesh's RMG industry from being a preferred source of import for apparel products.

\section{Cultural Variations}

Bangladesh is not familiar with the culture of remote markets and their customer's needs. These markets have different cultures and their choice of clothing is different from traditional market. Middle East has a complete different taste of clothing due to geographical and religious reasons from other 
parts of the world. Lack of proper understanding of their clothing needs lead to lower export to those markets.

\section{Violation of Compliance}

Social compliance is the basic criteria for a RMG industry and for its sustainable growth. When Bangladesh was moving fast, two fatal incidents brought a completely negative impression on Bangladeshi apparel industry. On 24 November, 2012, Tazreen Fashion fire broke out and more than 100 people died inside the factory as the exit was closed. On 24 April, 2013, Rana plaza collapsed resulting to the death of more than 1100 people and leaving more than 2500 people injured. These two incidents were widely discussed all over world in all types of media. Thus, these two incidents made a bad impression for the emerging markets to import from Bangladesh.

\section{Poor Internal Transportation Structure}

All the economic activities of Bangladesh are totally or partially connected to its capital city, Dhaka. The distance between Dhaka and the main export city, Chittagong, is approximately $264.99 \mathrm{~km}$. All the manufactured garments have to be transported this distance in order to be shipped. Although the distance seems short, the poor internal transportation network makes it a lot time consuming. This poor transportation network cuts some valuable time from the lead time. Sometimes, there are nationwide strikes which add to the distress.

\section{Lack of Utility Support}

The inadequate power and gas supply to RMG factories is hurting this sector. Bangladesh is expected to run out of natural gas in the near future. However, according to Petrobangla, $85 \%$ power plant is gas-based. The frequent power cuts and lower pressure of gas are putting machines to sleep and thus making the workers idle. According to BGMEA, $720 \mathrm{MW}$ of electricity is required by the RMG factories whereas the government is supplying some $406 \mathrm{MW}$. The natural gas is shared by both industrial and domestic sectors and, as a result, the supply of gas to industries is below the requirement. Many RMG factories may face closure due to high fuel costs.

\section{Justifications of Increasing Export}

\section{Competitive Advantage in Lead Time}

Lead time is a key factor in RMG exports. A manufacturer is committed to maintaining the lead time at any cost. Export to some nontraditional markets require less lead time than some traditional markets as those countries are not near to Bangladesh. The following table shows the time 
required to reach port of destination by sea from Chittagong port of Bangladesh:

Table 1. Lead time required to export to non-tradional markets (Source:ports.com)

\begin{tabular}{|c|c|}
\hline Country & Lead Time (Days) \\
\hline Turkey & 26.4 \\
\hline Japan & 22.5 \\
\hline South Africa & 28.2 \\
\hline South Korea & 21.2 \\
\hline Australia & 24.1 \\
\hline
\end{tabular}

\section{Increase in Labor Wage and Production Cost}

Recently, Bangladesh government has declared the new minimum wage structure for the Bangladeshi RMG workers. According to the new structure, minimum wage at the entry level will be US \$94.01, which increased $51 \%$ from the previous US $\$ 62.28$. This wage hike is certainly going to increase the cost of manufacturing for the factories. It will have a significant impact mostly on the small and medium type companies. Nevertheless, buyers are not willing to share the increased cost. As a result, it may decrease the orders in traditional market. Hence, Bangladesh need to quickly find out other markets as well to cover up the extra cost associated with this labor wage increase.

\section{Product Diversification}

The defined non-traditional markets have diversified and distinct culture. If Bangladesh can increase export to these countries, various cultural norms will help to enable the readymade garment producers in producing diversified products.

\section{Becoming a Global Brand}

Bangladesh has already established the tag "Made in Bangladesh", but still it has not become a one-stop solution to readymade garments globally. So through market exploration, many other countries will be linked to Bangladesh and would help it become a global brand for readymade garments.

\section{Human Capital Transformation}

Bangladesh is producing a huge number of educated workforce ready to enroll in the economic activity of the country. Since there is no enough job creation, the huge potential of this workforce is at risk of being underutilized.

\section{Conclusion}

In conclusion, it can be stated that it is high time to explore the nontraditional export destinations. Otherwise, the export target of reaching US $\$ 50$ billion by 2021 will be hard to achieve. To be able to retain the position 
of one of the top readymade garments exporters, Bangladesh needs to focus more on new marketing techniques to penetrate into non-traditional markets and secure sustainable exports.

\section{References:}

1. http://epb.gov.bd/site/view/epb_export_data/-

2. https://thefinancialexpress.com.bd/trade/dhaka-moscow-for-directbank-dealings-1538367663

3. https://www.fibre2fashion.com/industry-article/5613/turkey-pushesexporters-in-dire-strait-with-import-tariffs

4. https://www.dhakatribune.com/business/2017/02/20/garmentexporters-seek-duty-free-access-us-brazil-markets

5. https://www.couriersplease.com.au/Portals/0/images/Textile_Sample _Guideline_Dec2017.pdf

6. https://www.bgmea.com.bd/

7. http://ports.com/

8. https://www.dhakatribune.com/business/2019/04/26/apparel-sector-scontribution-to-gdp-going-down-for-years

9. Study of The Growth and Stagnation of the Garments Industry of Bangladesh- Syed Masum Ahmed Chowdhury

10. The RMG Sector: Prospects and Challenges and Role of Different Stakeholders-Syed Robayet Ferdous 